\title{
Design and Implementation of Home/Office Automation System based on Wireless Technologies
}

\author{
Manasee Patil \\ Final year MTech Student \\ IP University, New Delhi, India
}

\author{
S.R.N. Reddy \\ Associate professor, \\ IGDTUW, Delhi, India
}

\begin{abstract}
Home/office automation is currently a new growing field in Science: The goal of this automation is controlling the house elements lights, fans, air conditioner in order to save energy and raise the quality of living. In this project in order to make life easier some smart home applications are designed. In this project Home/office automation is done using wireless technologies. System is developed with automatic door opening and closing, temperature monitoring, gas detection and light controlling. Door opening and closing is controlled by RFID, ZigBee and GSM. Temperature monitoring gas detection and light controlling is developed using GSM.
\end{abstract}

\section{General terms}

Automation, wireless technologies, monitoring, controlling

\section{Keywords}

ZigBee, GSM, RFID

\section{INTRODUCTION}

The main purpose of this project is to allow users to be identified securely without being intruded by anyone and transmission of data in long distances to control the opening of magnetic sensor doors. Door opening and closing is controlled by RFID, ZigBee and GSM. Temperature monitoring gas detection and light controlling is developed using GSM.

Project consists of RFID tags and RFID reader in the system. RFID reader is connected to the microcontroller Rx and Tx pins through switching IC. When user wants to enter the room he/she can place his/her valid RFID card on the reader. If valid RFID card is detected by the system Gate opened and closed after some delay. If invalid card get detected alarm start ringing, so that we get information about invalid user.

ZigBee technology is used to open and close door from inside the home/office. Project has two ZigBee modules, one placed near the door system and other placed at remote place. Two switches are provided on ZigBee module to open and close the gate.

One can open and close the gate from outside the home/office by using GSM technology. Optocoupler sensors are used to detect no. of persons present in the room. Depending on no. of persons in the room light is controlled. If no. of persons are more than 1 then one light turned ON. If no. of persons are greater than 3 then two lights get turned ON. If no one is present in the room all lights turned OFF.

Finally room temperature monitoring and gas detection system is developed. If any combustible gas is detected in the room, message is sent to user about gas detection. So that user can do corrective action. Room temperature is exceeded than $30^{\circ} \mathrm{C}$, sms is sent to the user about the high room temperature.

\section{RELATED WORK}

Home automation is not only design concept now days. Home automation has direct impact on lifestyle of people. Goal of this automation is controlling the elements (lights, fans, air conditioners) in the house/office. Several home automation systems are developed. Different home automation systems were analyzed based on technology used, processor or controller used.

A digital door lock system was equipment that used the digital information such as a secret code, semi-conductors, smart card, and finger prints as the method for authentication instead of the legacy key system. As the door lock was the first and last thing people come across in entering and leaving the home respectively. Automatic door opening and closing is part of home automation. [1] [2] [8] [9] developed digital door lock system for home automation.

Functional, low cost and low complexity microcontroller based door access control system successfully presented by Oke et al.(2009). . They proposed security door system which adopted a valid smart card to authenticate and/or deny entry to a room or building. Verma and Tripathi (2010) ${ }^{[2]}$ implemented a digital security system contains door lock system using passive RFID. A centralized system was deployed for controlling and transaction operations. The door locking system functioning in real time, as when the user put the tag was in contact with the reader, the door opened. Sthapit (2009) ${ }^{[8]}$ proposed a smart digital door lock system for home automation In their proposed system, a ZigBee module was embedded in digital door lock and the door lock acts as a central main controller of the overall home automation system. In [9] the Automatic Door Opener was designed to pneumatically open or close a door by remote control using radio frequency communication technology. A fingerprint recognition system was also installed for security purposes preventing unauthorized users from gaining entry.

[2] [3] [4] [5] [8] [13] implemented secured and authenticate system using RFID. [2] Utilized RFID technology to provide solution for secure access of a space while keeping record of the user. A centralized system was deployed for controlling and transaction operations. Proposed system by Naveed et al. [5], was low cost identification and authentication system which was be deployed at doors of building to authenticate people. Proposed system was also accompanied with PC interfacing to see authentication details with date and time.

Zigbee based home automation System is proposed in [6],[7],[8],[10],[11],[13],[15],[17]. These systems use Zigbee for communicating between user and devices. This system allows user to monitor and control devices in the home through a number of controls, including a Zigbee based remote control. Users may remotely monitor and control their home devices.

A wireless-GSM based Home Security System is proposed in $[12,14,15,16,17] .[14]$ This system is a low-power 
consumption remote home security system developed by applying GSM technology which has the ability of wirelessly sending and receiving data, and can send a SMS to the user's mobile when some dangerous condition has been detected.

The target of controlling home appliances remotely using SMS-based system has achieved in [16] satisfying user needs and requirements. All electrical appliances can be controlled by sending a message from a mobile handset through GSM technology.

By combining wireless sensor network and GSM technology remote home security monitoring and alarming system is designed in [17]. This system can detect the theft, fire and send alarm message to house's owner. This system is based on both WSN and GSM technology. System has advantages of reliability, easy usage, complement wireless and low power consumption.
Door opening and closing is controlled by RFID, ZigBee and GSM. Temperature monitoring gas detection and light controlling is developed using GSM. RFID tags and RFID reader is used in the system. RFID reader is connected to the microcontroller Rx and Tx pins through switching IC. When user wants to enter the room he/she can place his/her valid RFID card on the reader. If valid RFID card is detected by the system Gate opened and closed after some delay. If invalid card get detected alarm start ringing, so that we get information about invalid user.

ZigBee technology is used to open and close door from inside the home/office. Two ZigBee modules are used, one placed near the door system and other placed at remote place. Two switches are provided on ZigBee module to open and close the gate.

\section{PROJECT DESCRIPTION}

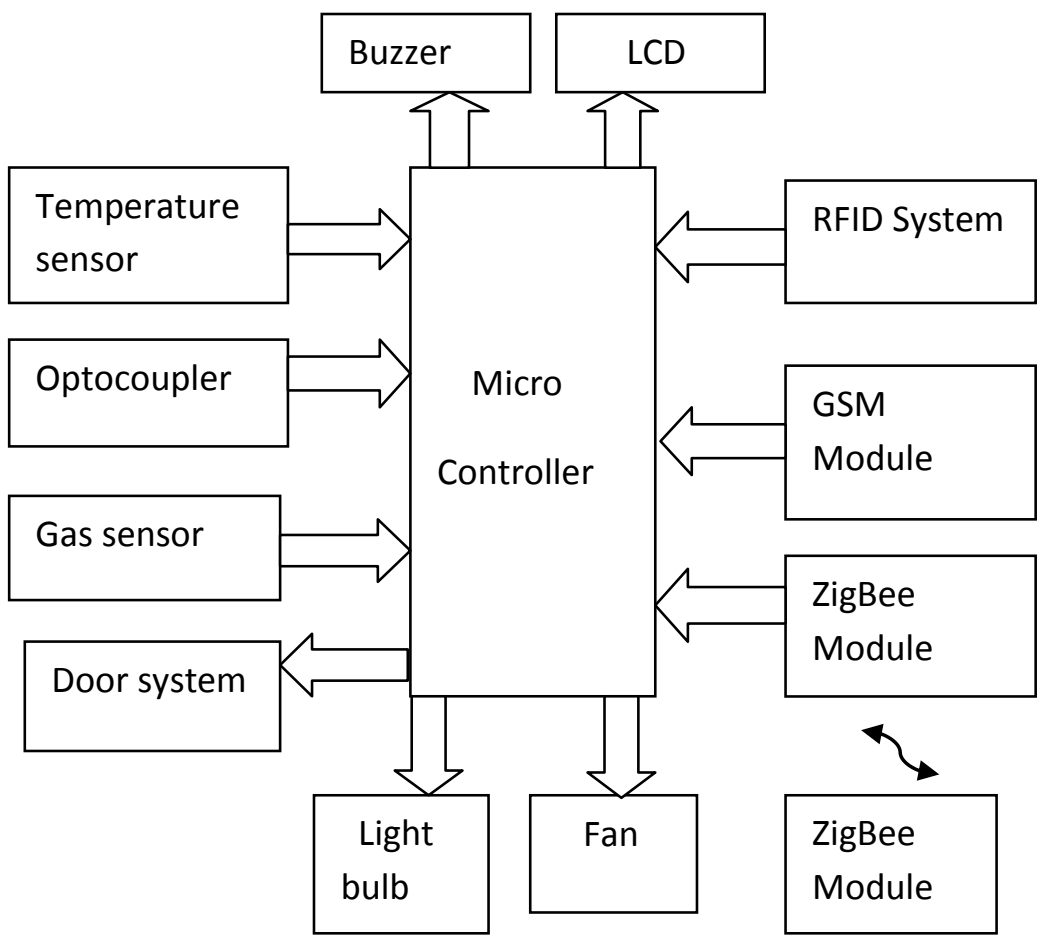

Figure1. Block diagram of Home/office automation system based on wireless technologies.

One can open and close the gate from outside the home/office by using GSM technology.

Optocoupler sensors are used to detect no. of persons present in the room. Depending on no. of persons in the room light is controlled. If no. of persons is more than 1 then one light turned ON. If no. of persons is greater than 3 then two lights get turned ON. If no one is present in the room all lights turned OFF.

Finally room temperature monitoring and gas detection system is developed. If any combustible gas is detected in the room, message is sent to user about gas detection.
So that user can do corrective action. Room temperature is exceeded than $30^{\circ} \mathrm{C}$, sms is sent to the user about high temperature.

\subsection{RFID Mode}

The working of the automatic gate control system is based upon programming in the microcontroller when a regulated supply is applied. The well regulated supply is given to the PIC16F877A.Then LCD will display a message "INSERT YOUR CARD". If a user sense the RFID card transmission and receiving of radio waves starts between the RFID tag and the reader. When the card is accepted then user can enter otherwise LCD will display unknown user

and card will be rejected. If card is rejected access to the door is denied and buzzer will start. If card is accepted signal is send to microcontroller to operate relay. On receiving signal from microcontroller relay operates to open the door. 
Microcontroller programmed with some delay to keep door open and after some delay door automatically closed.

\subsection{ZigBee Mode}

In this project ZigBee technology is used to open and close door from inside the home/office. Two ZigBee modules were used, one placed near the door system and other placed at remote place. Two switches are provided on ZigBee module to open and close the gate. Figure 2 shows interfacing of ZigBee module with Microcontroller. ZigBee module is connected to microcontroller pins 25 \& 26 i.e. Tx, Rx. ZigBee module consist of XBEE pro and max 232 for communication with microcontroller. Figure 2 shows connection diagram of ZigBee mode.

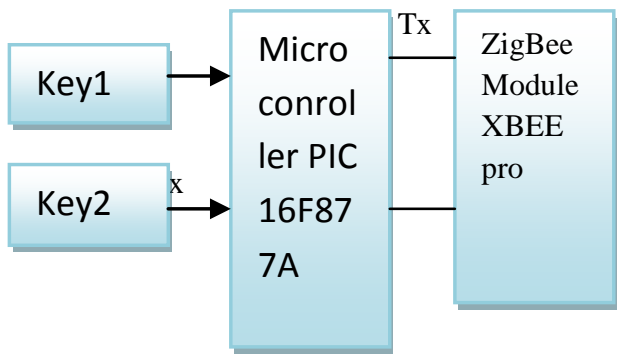

Figure.2 ZigBee module XBEE pro interfacing with Microcontroller

PIC board has three keys on it, one key to reset microcontroller other two keys to open and close the gate remotely. In XBEE mode we have ZigBee module placed at door we can call it as device node. If user wants to open and close door from remote place in home/office, key1 is pressed to open the door and key2 is pressed to close the door. When key is pressed signal is send to device node ZigBee wirelessly.

\subsection{GSM Mode}

In this mode we develop light controlling system using optocoupler, gas detection temperature monitoring with sensor LM35 and door opening and closing from outside the home/office. we use GSM modem SIM300 for communication between user and devices..

\subsubsection{Light controlling using Optocoupler}

In this project light is controlled by using optocoupler in GSM mode. Two optocouplers are used placed near door. Optocoupler are connected to microcontroller. This system counts no. of persons entering the room. We set counter in up/down mode. Counter increments if person entering the room and decrements when person leaving the room. Two devices connected at the output of the system fan and light bulb. We use two relays to connect devices. If count is increased by 1 , means one person is in the room, system turn on the fan. If count increases more than 3 then second relay is operated and light bulb turned ON. O You can connect more device to system to control light in the room. Figure 5.5 shows snapshot of light controlling system. First part shows no. of visitors displayed on LCD, visitor $=1$, Fan is ON. Second part shows count is 5, LCD displays visitor $=5$, Light turned $\mathrm{ON}$

\subsubsection{Gas detection circuit}


expansion of this work. The system can be expanded with further security measures can be taken by sending information to the emergency call centre using GSM technology. Information about fire can be send to fire station; intruder detection information can be send to police station. It is recommended to develop a system in which temperature monitoring and controlling is performed.

\section{ACKNOWLEDGEMENT}

I am grateful to Dr. S.R.N.Reddy, Associate. Professor at IGDTUW, for allowing me to do this project under his guidelines. Without his constant support encouragement and reliable suggestions, this write up would not become possible.

\section{REFERENCES}

[1] Oke, A.O., O.M. Olaniyi, O.T. Arulogun, and O.M. Olaniyan. 2009. "Development of a MicrocontrollerControlled Security Door System". Pacific Journal of Science and Technology. 10(2):398-403.

[2] Verma, G. K.; Tripathi, P., "A Digital Security System with Door Lock System Using RFID Technology", International Journal of Computer Applications (0975 8887), 2010, Vol5, pp 6-8.

[3] Salim G Shaikh and Shankar D Nawale.,"Secure access of RFID system", International Journal of Scientific \& Engineering Research, Volume 3, Issue 8, August-2012

[4] Parvety A,Venkata Rohit Raj,Venumadhav Reddy M, Manikanta Chaitanya G "RFID based exam hall maintenance system," IJCA Special Issue on "Artificial Intelligence Techniques - Novel Approaches \& Practical Applications "AIT, 2011

[5] Muhammad Naveed, Wasim Habib, Usman Masud, Ubaid Ullah, and Gulzar Ahmad," Reliable and Low Cost RFID Based Authentication System for Large Scale Deployment", International Journal of Network Security, Vol.14, No.3, PP. 173\{179, May 2012

[6] Y.Usha Devi," Wireless Home Automation System Using ZigBee", International Journal of Scientific \& Engineering Research Volume 3, Issue 8, August-2012 1 ISSN 2229-5518

[7] Michal VARCHOLA," Zigbee Based Home Automation Wireless Sensor Network", Acta Electrotechnica et Informatica No. 4, Vol. 7, 2007
[8] Yong Tae Park, Sthapit, P.;Jae-Yong Pyun, ," Smart digital door lock for the home automation", TENCON 2009-2009 IEEE Region 10 Conference Jan 2009.

[9] Pik-Yiu Chan, Enderle J. D.," Automatic door openr", Bioengineering conference 2000 proceeding of IEEE $26^{\text {th }}$ Annual Northeast 2000.

[10] Gill K. Shuang-Hua Yang; Fang Yao; Xin Lu,” ZigBee based Home Automation system", Consumer Electronics, IEEE Transaction on May 2009.

[11] Usha Sharma and SRN Reddy," Design of home/ office automation using wireless sensor network", International Journal of computer application, vol. 43, April 2012 pp.53-60.

[12] Vini madan, SRN Reddy," GSM-Bluetooth based remote monitoring and control system with automatic light controller", International journal of computer applications (0975-8887) vol. 46 no.1, 2012.

[13] Lie Zhang, Zhi Wang," Integration of RFID into wireless Sensor Network: architecture, opportunities and challenging problems", Fifth international conference on Grid and cooperative computing workshop (GCCW'06), 2006.

[14] Huiping Huang, Shide Xiao, Xiangyin Meng and Ying Xiong, "A Remote Home Security System Based on Wireless Sensor Network and GSM Technology", Second International Conference on Networks Security Wireless Communications and Truste d Computing 2010, vol 1, pp 535-538, April 201

[15] Ahmad.A.W, Jan. N., Iqbal S. and Lee C., “ Implementation of GSM-Zigbee based Home Security Monitoring and Remote Control System" IEEE $54^{\text {th }}$ International Midwest Symposium on Circuit and Systems, 2011, pp. 1-4.

[16] R.Chutia, D.Sonowal, S.Sharma," Remote household appliance control system using GSM", proc. Of international conference of advanced computing and communication technologies (ACCT 2011), 2011.

[17] Aayush Agarwal, R.C.Joshi,’WSN GSM based Remote Home security system", proc.International Conference on Recent advances and Future Trends in Information technology (IRAFIT 2012). 